\title{
Interferência de culturas anuais no crescimento inicial de Brachiaria ruziziensis
}

\author{
Luan Marlon Ribeiro ${ }^{1}$, Ericksson Martins Leite², Gessí Ceccon ${ }^{3}$ \\ ${ }^{1}$ Universidade Federal da Grande Dourados, Dourados, Mato Grosso do Sul, Brasil. E-mail: luanmarlon@hotmail.com \\ ${ }^{2}$ Universidade Estadual de Mato Grosso do Sul, Aquidauana, Mato Grosso do Sul, Brasil. E-mail: eml_eftal@ hotmail.com \\ ${ }^{3}$ Empresa Brasileira de Pesquisa Agropecuária - Embrapa Agropecuária Oeste - CPAO, Dourados - MS, Brasil. E-mail: \\ gessi.ceccon@embrapa.br
}

Recebido: 05/09/2017; Aceito: 18/04/2018.

\section{RESUMO}

Objetivou-se avaliar o crescimento inicial da B. ruziziensis consorciada com espécies anuais. O experimento foi conduzido na Embrapa Agropecuária Oeste, em Dourados-MS. Em 18/05/2014 semeou-se a B. ruziziensis solteira e consorciada com aveia branca, trigo, canola, girassol, crambe e Crotalaria ochroleuca, com seis plantas por vaso; e milheto, feijão-caupi, feijão-comum, sorgo sacarino e milho com quatro plantas por vaso, contendo $30 \mathrm{~kg}$ de solo seco. O arranjo experimental foi em esquema fatorial $2 \times 12$ (Solos (argiloso e arenoso) e Culturas), em blocos casualizados, com três repetições. Aos 55 dias após a semeadura das culturas avaliou-se o crescimento, massa seca de plantas, número de perfilho e altura da braquiária; área foliar e massa seca das culturas anuais. Calculou-se a massa seca de braquiária no consórcio em relação ao seu cultivo solteiro. Os dados foram submetidos a análise de variância e as médias agrupadas pelo teste de Scott-Knott $(\mathrm{p}<0,05)$. A braquiária produziu $78 \%$ e $55 \%$ em massa; e 2,2 e 1,6 perfilho por planta, no solo argiloso e arenoso, respectivamente. A produtividade de massa de braquiária foi aumentada no consórcio com C. ochroleuca (14\%) e diminuída no consórcio com milho (29\%), girassol (32\%), feijão-caupi (34\%), aveia branca (51\%), feijão comum (52\%), canola (57\%) e sorgo sacarino (67\%), com redução também no seu perfilhamento.

Palavras-chave: Alelopatia, consórcio, integração-lavoura-pecuária.

\section{Interference of annual crops on initial growth of Brachiaria ruziziensis}

\begin{abstract}
The objective of this study was to evaluate the initial growth of ruzigrass (B. ruziziensis) with annual species. The experiment was conducted at Embrapa Agropecuária Oeste, in Dourados, MS, Brazil. On May 18, 2014 sowed $B$. ruziziensis single and intercropping with white oats, wheat, canola, sunflower, crambe and Crotalaria ochroleuca, with six plants per pot; and millet, cowpea, common bean, sorghum and maize with four plants per pot containing $30 \mathrm{~kg}$ of dry soil. The experimental arrangement was in a 2x12 factorial scheme [ two soil type (clayey and sandy) and twelve crops], in a randomized block design, with three replications. At 55 days after sowing the crops, the plant dry mass, number of tiller and height of the ruzigrass were evaluated; leaf area and dry mass of annual crops. The dry mass of ruzigrass was calculated in the intercropping in relation to its single crop. The data were submitted to analysis of variance and the means grouped by the Scott-Knott test $(\mathrm{p}<0.05)$. The ruzigrass produced $78 \%$ and $55 \%$ by mass; and 2.2 and 1.6 tillers per plant in the clayey and sandy soil, respectively. The matter yield of ruzigrass was increased in the intercropping with C. ochroleuca (14\%) and decreased in the intercropping with maize (29\%), sunflower (32\%), cowpea (34\%), white oats (51\%), common bean (52\%), canola (57\%) and sorghum $(67 \%)$, with reduction also in its tillering.
\end{abstract}

Keywords: Allelopathy, intercropping, integration crop farming. 


\section{Introdução}

O consórcio entre culturas é praticado a muito tempo por pequenos produtores, usando duas ou mais culturas no mesmo espaço disponível, visando a diversificação na renda familiar (Garcia et al., 2013). Os primeiros registros de consórcio entre culturas anuais e forrageiras perenes no Cerrado, foi na década de 1990, denominado de Sistema Barreirão, consistia na correção do solo com preparo mecanizado, antecedendo a cultura de verão (Oliveira et al., 1996), com o passar do tempo, surgiram outras propostas para Integração Lavoura-Pecuária (ILP), com rotação lavoura-pastagem, e em 2001 surgiu o Sistema Santa Fé, que consistia na produção consorciada de culturas de grãos, especialmente o milho e a soja com forrageiras tropicais, produzindo forragem para entressafra (Kluthcouski et al., 2013).

No Cerrado brasileiro, o consórcio mais utilizado tem sido milho-braquiária, objetivando a produção de grãos de soja em Sistema Plantio Direto (SPD), mantendo o solo, permanentemente coberto (Concenço et al., 2012). No entanto o objetivo final é determinante para a implantação do sistema, pois no consórcio de culturas anuais com forrageiras perenes, tem como objetivo a produção de palhada para a cobertura do solo e a produção de forragem para alimentação de animais (Ceccon et al., 2010).

Várias outras culturas tem sido avaliadas em condições de consórcio com a Brachiaria, por ser uma espécie recomendada para o sistema de integração lavoura-pecuária (Montezano e Peil, 2006), no entanto, forrageiras do gênero Brachiaria hoje disponíveis no mercado, não foram selecionadas para uso de integração lavoura-pecuária e muito menos para o estabelecimento de consórcio com culturas anuais, mas conhecendo as características tanto das forrageiras quanto das culturas anuais, é possível escolher aquelas que são mais adequadas para tais finalidades (Machado et al., 2013).

Esse sistema integrado entre culturas anuais e forrageiras perenes em SPD tem surgido como uma alternativa para recuperação dos solos degradados, por manter palha na superfície do solo, proporcionando diminuição da densidade da camada superficial, maior infiltração da água e aeração, favorecendo o desenvolvimento do sistema radicular (Silva et al., 2011), além de promover benefícios às culturas subsequentes (Ceccon et al., 2013). Loos et al. (2012) verificaram melhorias nos atributos físicos do solo em SPD através da adição de matéria orgânica ao solo, resultando em melhores condições para as culturas em sucessão.

Outro fator importante que devesse levar em consideração, principalmente no momento da escolha das culturas para o sistema integrado é a competição direta e a alelopatia (Silva et al., 2013). Na competição, temos entre plantas (intraespecífica) e com outras plantas (interespecíficas) pelos recursos do meio (luz, água, nutrientes, $\mathrm{CO}_{2}$, etc.), essa competição determina prejuízos no crescimento, no desenvolvimento e na produção das culturas (Zanine e Santos, 2004). Com relação à alelopatia, define-se como a influência de um indivíduo ao outro, seja prejudicando ou favorecendo, esse efeito é realizado por biomoléculas (denominadas aleloquímicos), produzidas por plantas que são acumuladas no solo ou lançadas no ambiente (Rizvi et al., 1992; Akira Ito et al., 2015).

Dessa forma objetivou-se com este trabalho avaliar a interferência de culturas anuais sobre o crescimento inicial de Brachiaria ruziziensis.

\section{Material e Métodos}

O experimento foi desenvolvido na Embrapa Agropecuária Oeste, no município de Dourados, Mato Grosso do Sul, nas coordenadas $22^{\circ} 13^{\prime} \mathrm{S}$ e $54^{\circ} 48^{\prime} \mathrm{W}$, e conduzido em casa telada não climatizada.

$\mathrm{O}$ arranjo experimental foi em esquema fatorial $2 \times 12$ (Solos e Culturas), no delineamento de blocos casualizados, com três repetições. Em 18/05/2014 semeou-se a Brachiaria ruziziensis solteira e consorciada com aveia branca, trigo, canola, girassol, crambe e Crotalaria ochroleuca, com seis plantas por vaso; e milheto, feijão-caupi, feijão comum, sorgo sacarino e milho com quatro plantas por vaso.

Utilizou-se vasos cilíndricos com capacidade de 30 $\mathrm{kg}$ de solo seco $(40 \times 60 \mathrm{~cm}$ ), os solos utilizados foram classificados como Latossolo Vermelho distroférrico LVdf (argiloso) e Latossolo Vermelho distrófico - LVd (arenoso), foram coletados na área experimental da Embrapa Agropecuária Oeste em Dourados-MS e no município de Fátima do Sul-MS, respectivamente. Uma sub amostra foi levada para o laboratório de fertilidade e física do solo da Embrapa Agropecuária Oeste, para a caracterização química (Tabela 1), seguindo metodologia descrita por Embrapa (1997).

$\mathrm{Na}$ semeadura das culturas, não foi utilizado nenhuma forma de adubação. No entanto, a irrigação aconteceu periodicamente de forma manual, mantendo a umidade próxima às condições de campo.

Aos 55 dias após a semeadura das culturas, foi realizado a coleta das plantas, onde foram levadas para o laboratório, e avaliado a altura, número de perfilho e massa seca da braquiária; área foliar e massa seca das culturas anuais.

Altura de plantas da braquiária e das culturas anuais foi determinada com a medição do comprimento da base até o ápice da planta e posteriormente contou-se o número de perfilhos da forrageira. Para a taxa de crescimento da braquiária, calculou-se a massa seca de braquiária no consórcio em relação ao seu cultivo quando solteiro. 
Tabela 1. Caracterização química do solo utilizado no experimento, em Dourados-MS, 2018

\begin{tabular}{|c|c|c|c|c|c|c|c|c|c|c|c|c|c|}
\hline Solo & $\mathrm{pH}$ & $\mathrm{Al}$ & $\mathrm{Ca}$ & $\mathrm{Mg}$ & $\mathrm{K}$ & CTC & $\mathrm{V}$ & M.O. & $\mathrm{P}$ & $\mathrm{Cu}$ & $\mathrm{Fe}$ & $\mathrm{Mn}$ & $\mathrm{Zn}$ \\
\hline & $\mathrm{H}_{2} \mathrm{O}$ & & ........ & $\mathrm{cmol}$ & & 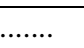 & $\%$ & $\mathrm{~g} \mathrm{~kg}^{-1}$ & $\ldots .$. & $\ldots$ & $\mathrm{mg} \mathrm{d}$ & & \\
\hline $\operatorname{LVdf}^{*}$ & 5,8 & 0,1 & 4,0 & 1,2 & 0,63 & 11,7 & 50 & 29,7 & 37,5 & 11,0 & 30,7 & 51,3 & 4,6 \\
\hline $\mathrm{LVd}^{* *}$ & 6,1 & 0,0 & 3,3 & 0,8 & 0,29 & 7,0 & 63 & 15,4 & 15,8 & 8,9 & 12,7 & 86,1 & 7,6 \\
\hline
\end{tabular}

$\mathrm{Al}^{3+}, \mathrm{Ca}^{2+} \mathrm{e} \mathrm{Mg}^{2+}$ extraídos por KCl $1 \mathrm{~mol} \mathrm{~L}{ }^{-1} ; \mathrm{P}, \mathrm{K}, \mathrm{Cu}, \mathrm{Fe}$, Mn e $\mathrm{Zn}$ extraídos por $\mathrm{HCl}$ 0,05 mol L ${ }^{-1}+\mathrm{H}_{2} \mathrm{SO}_{4} 0,0125 \mathrm{~mol} \mathrm{~L}^{-1} \mathrm{e}$ carbono orgânico por oxidação com dicromato de potássio. "Latossolo Vermelho distroférrico (LVdf), coletado em Dourados, MS. * Latossolo Vermelho distrófico (LVd), coletado em Fátima do Sul, MS.

Para área foliar das culturas anuais, foi utilizado aparelho da marca LI-COR ${ }^{\circledR}$, modelo LI 3100 , que por meio de resolução entre a área $\mathrm{x}$ comprimento $\mathrm{x}$ largura máxima $\mathrm{x}$ largura média da folha, determinou área foliar em $\mathrm{cm}^{2}$. A massa verde fresca das plantas foi determinada por meio de balança semi-analítica, e posteriormente levadas para estufa de ar forçado a $65^{\circ} \mathrm{C}$ até peso constante, onde foram obtidas a massa seca das plantas.

Os resultados foram transformados para $\sqrt{ }(\mathrm{x}+1) \mathrm{e}$, a seguir, submetidos à análise de variância pelo teste $\mathrm{F}$ $(p<0,05)$ e quando significativos foram comparados pelo teste de Scott-Knott $(\mathrm{p}<0,05)$, com auxílio do programa SISVAR (Programa de Análises Estatísticas versão 5.3. Universidade Federal de Lavras, MG).

\section{Resultados e Discussão}

A análise de variância indicou efeito isolado de solos para taxa de crescimento, número de perfilho, altura da braquiária e das culturas anuais. Houve efeito isolado de culturas para crescimento e número de perfilho da braquiária, altura de culturas anuais e área foliar, massa seca da braquiária e culturas anuais, e massa seca total. Não houve interação entre solos e culturas para as variáveis analisadas (Tabela 2).

$O$ tipo de solo influenciou significativamente o desenvolvimento da braquiária, onde o solo argiloso, possivelmente pela maior fertilidade proporcionou maior taxa de crescimento das plantas $(78,6 \%)$ e maior número de perfilho $(2,26)$ da braquiária. De acordo com Gregory (1994), o desenvolvimento, crescimento e distribuição das raízes das plantas são afetados pela quantidade, forma e distribuição de nutrientes no solo. No entanto, o solo arenoso proporcionou condições para a maior altura de plantas da braquiária $(42,6 \mathrm{~cm})$ e das culturas anuais (38,8 cm). Segundo Macedo (2009), em solos com menor fertilidade como solos arenosos, este fenômeno pode acontecer, plantas com maior altura, mas que não se refletem em maior produtividade em massa e que o pleno desenvolvimento das plantas, especialmente em camadas superficiais estão diretamente relacionados com a fertilidade do solo (Tabela 3).

Tabela 2. Resumo da análise de variância para taxa de crescimento da braquiária (Cres braq), número de perfilho da braquiária $\left(\mathrm{N}^{\circ}\right.$ perf braq), altura de planta da braquiária (AP braq), altura de planta das culturas anuais (AP cult), área foliar das culturas anuais (AF cult), massa seca da braquiária (MSB), massa seca das culturas anuais (MSC) e massa seca total da braquiária mais as culturas anuais (MST), em Dourados-MS, 2018

\begin{tabular}{|c|c|c|c|c|c|}
\hline \multirow[b]{2}{*}{ Fator de Variação } & \multirow[b]{2}{*}{ GL } & \multicolumn{4}{|c|}{ 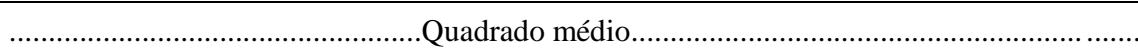 } \\
\hline & & Cres braq & $\mathrm{N}^{\circ}$ perf braq & AP braq & AP cult \\
\hline Bloco & 2 & 33,40 & 0,07 & 0,86 & 1,89 \\
\hline Solos & 1 & $56,20^{*}$ & $0,50 *$ & $6,77 *$ & $54,66^{*}$ \\
\hline Culturas & 11 & $18,70^{*}$ & $0,16^{*}$ & $0,74^{\mathrm{ns}}$ & $5,11 *$ \\
\hline Solos x Culturas & 11 & $4,20^{\mathrm{ns}}$ & $0,03^{\mathrm{ns}}$ & $0,38^{\mathrm{ns}}$ & $11,50^{\mathrm{ns}}$ \\
\hline Média Geral & & 66,82 & 1,97 & 39,22 & 36,64 \\
\hline \multirow[t]{2}{*}{ C.V. $(\%)$} & & 25,58 & 12,77 & 12,74 & 10,27 \\
\hline & & \multicolumn{4}{|c|}{ 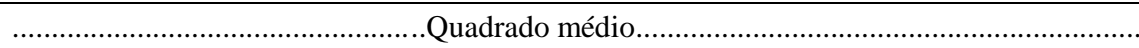 } \\
\hline Fator de Variação & GL & AF cult & MSB & MSC & MST \\
\hline Bloco & 2 & 4,38 & 0,06 & 0,00 & 0,02 \\
\hline Solos & 1 & $6,10^{\mathrm{ns}}$ & $0,39^{\text {ns }}$ & $0,29^{\mathrm{ns}}$ & $0,36^{\mathrm{ns}}$ \\
\hline Culturas & 11 & $1004,26^{*}$ & $0,47 *$ & $3,25 *$ & $1,24 *$ \\
\hline Solos x Culturas & 11 & $43,09^{\mathrm{ns}}$ & $0,15^{\mathrm{ns}}$ & $0,20^{\mathrm{ns}}$ & $0,24^{\mathrm{ns}}$ \\
\hline Média Geral & & 637,30 & 2,41 & 6,08 & 8,49 \\
\hline C.V. $(\%)$ & & 24,42 & 15,33 & 17,94 & 14,96 \\
\hline
\end{tabular}

GL = graus de liberdade, ${ }^{*}$ Significativo e ${ }^{\text {ns }}$ não significativo $(\mathrm{p}<0,05)$. 
Tabela 3. Taxa de crescimento da braquiária (Cresc braq), número de perfilho da braquiária ( $\mathrm{N}^{\circ}$ perf braq), altura de planta da braquiária (AP braq) e altura de plantas das culturas (AP cult) em função do tipo de solo, em Dourados-MS, 2018

\begin{tabular}{lcccc}
\hline Solos & $\begin{array}{c}\text { Cresc braq } \\
(\%)\end{array}$ & $\begin{array}{c}\mathrm{N}^{\circ} \text { perf braq } \\
\left(\text { planta }^{-1}\right)\end{array}$ & $\begin{array}{c}\text { AP braq } \\
(\mathrm{cm})\end{array}$ & $\begin{array}{c}\text { AP cult } \\
(\mathrm{cm})\end{array}$ \\
\hline Argiloso & $78,6 \mathrm{a}$ & $2,26 \mathrm{a}$ & $35,8 \mathrm{~b}$ & $34,4 \mathrm{~b}$ \\
Arenoso & $55,0 \mathrm{~b}$ & $1,69 \mathrm{~b}$ & $42,6 \mathrm{a}$ & $38,8 \mathrm{a}$ \\
Média Geral & 66,8 & 1,9 & 39,2 & 36,6 \\
C.V. $(\%)$ & 25,58 & 12,77 & 12,74 & 10,27 \\
\hline
\end{tabular}

Médias seguidas de mesma letra na coluna, não diferem pelo teste de Scott-Knott $(\mathrm{p}<0,05)$.

Tabela 4. Taxa de crescimento da braquiária (Cres braq), número de perfilho da braquiária ( $\mathrm{N}^{\circ}$ perf braq), área foliar das culturas (AF cult) e altura de plantas das culturas (AP cult) em função aos cultivos anuais, em Dourados-MS, 2018

\begin{tabular}{|c|c|c|c|c|}
\hline Culturas anuais & $\begin{array}{c}\text { Cres braq } \\
(\%)\end{array}$ & $\begin{array}{c}\mathrm{N}^{\circ} \text { perf braq } \\
\left(\text { planta }^{-1}\right)\end{array}$ & $\begin{array}{l}\text { AF cult } \\
\left(\mathrm{cm}^{2}\right)\end{array}$ & $\begin{array}{l}\text { AP cult } \\
(\mathrm{cm})\end{array}$ \\
\hline Brachiaria ruziziensis & $100,0 \mathrm{a}$ & $2,52 \mathrm{a}$ & - & - \\
\hline Aveia branca & $51,3 \mathrm{~b}$ & $1,00 \mathrm{~b}$ & $231,6 \mathrm{~d}$ & $34,7 \mathrm{c}$ \\
\hline Trigo & $94,1 \mathrm{a}$ & $2,05 \mathrm{~b}$ & $11,6 \mathrm{~d}$ & $24,8 \mathrm{c}$ \\
\hline Canola & $57,5 \mathrm{~b}$ & $1,63 \mathrm{~b}$ & $850,6 \mathrm{c}$ & $21,3 \mathrm{c}$ \\
\hline Girassol & $32,2 \mathrm{~b}$ & $1,21 \mathrm{~b}$ & $1377,4 \mathrm{~b}$ & $28,7 \mathrm{c}$ \\
\hline Crambe & $87,7 \mathrm{a}$ & $1,97 \mathrm{~b}$ & $487,4 \mathrm{~d}$ & $58,8 \mathrm{a}$ \\
\hline Milheto & $80,4 \mathrm{a}$ & $2,62 \mathrm{a}$ & $426,0 \mathrm{~d}$ & $63,7 \mathrm{a}$ \\
\hline Feijão-caupi & $34,7 \mathrm{~b}$ & $1,75 \mathrm{~b}$ & $963,2 \mathrm{c}$ & $30,0 \mathrm{c}$ \\
\hline Feijão comum & $52,3 \mathrm{~b}$ & $1,62 \mathrm{~b}$ & $2172,7 \mathrm{a}$ & $31,5 \mathrm{c}$ \\
\hline Sorgo sacarino & $67,4 \mathrm{~b}$ & $2,87 \mathrm{a}$ & $201,4 \mathrm{~d}$ & $46,2 \mathrm{~b}$ \\
\hline Milho & $29,5 \mathrm{~b}$ & $1,79 \mathrm{~b}$ & $585,2 \mathrm{c}$ & $53,3 \mathrm{~b}$ \\
\hline Crotalaria ochroleuca & 114,8 a & $2,52 \mathrm{a}$ & $340,6 \mathrm{~d}$ & $46,8 \mathrm{~b}$ \\
\hline Média Geral & 66,8 & 1,9 & 637,3 & 36,6 \\
\hline C.V. $(\%)$ & 25,58 & 12,77 & 24,42 & 10,27 \\
\hline
\end{tabular}

Médias seguidas de mesma letra na coluna, não diferem pelo teste de Scott-Knott $(\mathrm{p}<0,05)$.

Além da fertilidade do solo, esses resultados também podem estar relacionados com o fato de plantas vizinhas (mesmo sendo da mesma espécie) interferirem no desenvolvimento de outras plantas, pela produção de substâncias alelopáticas que apresentam efeito direto ou indireto, benéfico ou maléfico por intermédio da produção de compostos químicos liberados no solo (Silva et al., 2013). Segundo Cobucci (2001), a braquiária tem sido recomendadas para a implantação de cultivos consorciados, visando a diversificação da produção agropecuária. $\mathrm{O}$ autor salienta que em cultivos consorciados, seu estabelecimento anual ocorre sob condições de competição.

O feijão comum $\left(2172,7 \mathrm{~cm}^{2}\right)$, seguido do girassol $\left(1377,4 \mathrm{~cm}^{2}\right)$ apresentaram os melhores resultados de área foliar das culturas anuais, com reflexo negativo no número de perfilhos da braquiária consorciada. As forrageiras podem sofrer forte competição em cultivos consorciados com as culturas anuais durante seu ciclo de convivência (Portes et al., 2000), como na diminuição da sua capacidade fotossintética devido ao excesso de sombreamento, resultando em baixa produtividade em massa devido ao baixo ponto de compensação luminoso (Dias Filho, 2002) (Tabela 4).
Autores como Gimenes et al. (2008) afirmam que culturas anuais que apresentam maior área foliar, acabam por impedir nas entrelinhas de plantio a incidência de luz direta sobre as forrageiras, acarretando menores taxas de crescimento por parte das forrageiras.

A maior altura de planta das culturas anuais foi obtida somente para milheto $(63,7 \mathrm{~cm})$ e crambe $(58,8$ $\mathrm{cm})$. Forrageiras perenes do gênero Brachiaria podem afetar negativamente por meio dos efeitos alelopáticos a germinação de sementes, crescimento e/ou desenvolvimento de plantas vizinhas (Rodrigues et al., 2012). No entanto, através dos resultados obtidos neste experimento, não se verificou efeito da Brachiaria ruziziensis sobre crambe e milheto para altura de plantas das culturas anuais. Busato e Busato (2011) salientam que o conhecimento de como consorciar culturas anuais e forrageiras perenes, são importantes para diminuir fatores de competição, para que se tenha êxito na formação de pastagem e produção satisfatória de grãos.

As culturas como girassol $(11,15 \mathrm{~g})$ e feijão comum $(12,43 \mathrm{~g})$, demonstraram melhores resultados para massa seca das culturas anuais, possivelmente pelos melhores resultados de área foliar nessas culturas, havendo reflexos negativos no crescimento inicial da 
braquiária. Segundo Freitas et al. (2008), ocorre um rápido fechamento das entrelinhas dessas culturas anuais devido a maior área foliar, ocorrendo a competição interespecífica, impedindo dessa forma a incidência de luz sobre as forrageiras, acarretando em menor taxa de crescimento da braquiária (Tabela 5). A B. ruziziensis quando solteira $(4,32 \mathrm{~g})$ ou consorciada com milho (4,08 g), obtiveram melhores resultados de massa seca da braquiária. Devido ao vigor das plântulas de milho terem sido maiores, possivelmente acarretou maior sombreamento sobre as plântulas de braquiária, o que ocasionou estiolamento da forrageira em busca de luz, aumentando o comprimento e consequente massa verde da forrageira. Conhecendo as características de cada cultivo, especialmente de B. ruziziensis com milho, estas podem ser consorciadas sem prejuízo para ambas as culturas (Görgen et al., 2010). Freitas et al. (2008) avaliando a semeadura simultânea de consórcio entre forrageiras cultivadas na entrelinhas do milho, não verificaram diminuição no rendimento da cultura.

Segundo Mendonça et al. (2014) as diferenças na produção do milho consorciado com forrageiras, variarão em função da espécie forrageira associada à cultura anual, das condições locais e do método de semeadura.

Com relação à massa seca total, Brachiaria ruziziensis consorciada com girassol $(12,48 \mathrm{~g})$, crambe $(10,11 \mathrm{~g})$ e feijão comum $(14,02 \mathrm{~g})$, obtiveram os melhores resultados, esse desempenho está relacionado com a massa seca das culturas anuais, onde essas culturas apresentaram melhores resultados. A reserva nutritiva das sementes das culturas anuais quando comparado às forrageiras é grande, e somado ao maior volume do sistema radicular, contribui para seu maior crescimento inicial, aumentando a produtividade em massa (Gimenes et al., 2008).

Tabela 5. Massa seca das culturas (MSC), massa seca da braquiária (MSB) e massa seca total (MST) em função aos cultivos anuais, em Dourados-MS, 2018

\begin{tabular}{|c|c|c|c|}
\hline Culturas anuais & $\begin{array}{c}\text { MSC } \\
\text { (g/vaso) }\end{array}$ & $\begin{array}{c}\text { MSB } \\
\text { (g/vaso) }\end{array}$ & $\begin{array}{c}\text { MST } \\
\text { (g/vaso) }\end{array}$ \\
\hline Brachiaria ruziziensis & - & $4,32 \mathrm{a}$ & $4,32 \mathrm{c}$ \\
\hline Aveia branca & $6,58 b$ & $2,78 \mathrm{~b}$ & $8,32 \mathrm{~b}$ \\
\hline Trigo & $1,42 \mathrm{c}$ & $1,43 \mathrm{c}$ & $4,79 \mathrm{c}$ \\
\hline Canola & $6,79 b$ & $1,50 \mathrm{c}$ & $8,90 \mathrm{~b}$ \\
\hline Girassol & $11,15 \mathrm{a}$ & $2,18 \mathrm{c}$ & $12,48 \mathrm{a}$ \\
\hline Crambe & $6,99 \mathrm{~b}$ & $2,77 \mathrm{~b}$ & $10,11 \mathrm{a}$ \\
\hline Milheto & $5,61 \mathrm{~b}$ & $1,63 \mathrm{c}$ & $8,30 \mathrm{~b}$ \\
\hline Feijão-caupi & $6,78 \mathrm{~b}$ & $2,70 \mathrm{~b}$ & $7,98 \mathrm{~b}$ \\
\hline Feijão comum & $12,43 \mathrm{a}$ & $1,29 \mathrm{c}$ & $14,02 \mathrm{a}$ \\
\hline Sorgo sacarino & $3,33 \mathrm{c}$ & $1,07 \mathrm{c}$ & $5,56 \mathrm{c}$ \\
\hline Milho & $7,90 \mathrm{~b}$ & $4,08 \mathrm{a}$ & $8,94 \mathrm{~b}$ \\
\hline Crotalaria ochroleuca & $4,05 \mathrm{c}$ & $3,14 \mathrm{~b}$ & $8,14 \mathrm{~b}$ \\
\hline Média Geral & 6,08 & 2,41 & 8,49 \\
\hline C.V. $(\%)$ & 17,94 & 15,33 & 14,96 \\
\hline
\end{tabular}

Médias seguidas de mesma letra na coluna, não diferem pelo teste de Scott-Knott $(\mathrm{p}<0,05)$.

\section{Conclusões}

Os melhores resultados foram obtidos em solo argiloso.

Culturas como feijão comum, girassol, feijão-caupi, canola, aveia branca e sorgo sacarino, apresentaram interferência ao crescimento inicial de $B$. ruziziensis.

Crotalaria ochroleuca, trigo, crambe e milheto não apresentaram restrições para o crescimento inicial de $B$. ruziziensis.

A cultura do milho não apresentou redução na produção inicial de massa seca de B. ruziziensis.

\section{Referências Bibliográficas}

Akira Ito, M., Concenço, G., Marques, R.F., Santos, S.A., Alves, M.E.S., Palharini, W.G., Melo, T.S., Silva, L.B.X., Linhares, L.T., Concenço, S.E., 2015. Allelopathic potential of wheat on sourgrass resistant to glyphosate. American Journal of Plant Sciences, 6, 891-898.
Busato, C., Busato, C.C.M., 2011. Crescimento inicial da cultura do milho em cultivo consorciado. Enciclopédia Biosfera: Centro Cientifico Conhecer, 7, 307-316.

Ceccon, G., Palombo, L., Matoso, A.O., Neto Neto, A.L., 2010. Uso de herbicidas no consórcio de milho safrinha com Brachiaria ruziziensis. Planta Daninha, 28, 359-364.

Ceccon, G., Staut, L.A., Sagrilo, E., Machado, L.A., Nunes, D.P., Alves, V.B., 2013. Legumes and forage species sole or intercropped with corn in soybean-corn succession in Midwestern Brazil. Revista Brasileira de Ciência do Solo, 37, 204-212.

Cobucci, T., 2001. Manejo integrado de plantas daninhas em sistema de plantio direto, In: Zambolin, L., (Ed.), Manejo Integrado. Fitossanidade: cultivo protegido, pivô central e plantio direto. Viçosa-MG., UFV, pp. 722.

Concenço, G., Ceccon, G., Fonseca, I.C., Leite, L.F., Schwerz, F., Correia, I.V.T., 2012. Weeds infestation in corn intercropped with forages at different planting densities. Planta Daninha, 30, 721-728. 
Dias Filho, M.B., 2002. Photosynthetic light response of the C4 grasses Brachiaria brizantha and Brachiaria humidicola under shade. Scientia Agrícola, 59, 65-68.

Embrapa. Empresa Brasileira de Pesquisa Agropecuária., 1997. Manual de métodos de análise de solo. Rio de JaneiroRJ: EMBRAPA-Centro Nacional de Pesquisa de Solos.

Freitas, F.C.L., Santos, M.V., Machado, A.F.L., Ferreira, L.R., Freitas, M.A.M., Silva, M.G.O., 2008. Comportamento de cultivares de milho no consórcio com Brachiaria brizantha na presença e ausência de foramsulfuron + iodosulfuron-methyl para o manejo da forrageira. Planta Daninha, 26, 215-221.

Garcia, C.M.P., Andreotti, M., Teixeira Filho, M.C.M., Buzetti, S., Celestino, T.S., Lopes, K.S.M., 2013. Desempenho agronômico da cultura do milho e espécies forrageiras em sistemas de Integração Lavoura-Pecuária no Cerrado. Ciência Rural, 43, 589-595.

Gimenes, M.R., Victoria Filho R., Prado, E.P., Dal Pogetto, M.H.F.A., Christovam, R.S., 2008. Interferência de espécies forrageiras com a cultura do milho. Revista da Faculdade de Zootecnia, Veterinária e Agronomia, 15, 61-76.

Zanine, A.M., Santos, E.M., 2004. Competição entre espécies de plantas. Revista da FZVA, 11, 10-30

Görgen, C.A., Civardi, E.A., Ragagnin, V.A., Silveira Neto, A.N., Carneiro, L.C., Lobo Junior, M., 2010. Redução do inóculo inicial de Sclerotinia sclerotiorum em soja cultivada após uso do sistema santa fé. Pesquisa Agropecuária Brasileira, 45, 1102-1108.

Gregory, P.J., 1994. Root growth and activity. in: Boote, K.J., Bennett, J.M., Sinclair, T.R., Paulsen, G.M., (Ed.), Phisiology and determination of crop yield. Madison: American Society of Agronomy, pp. 65-93.

Kluthcouski, J., Cordeiro, L.A.M., Ceccon, G., Oliveira, P., 2013. Braquiária na agropecuária brasileira: uma história de sucesso. in: Ceccon, G., (Ed.), Consórcio milho-braquiária. Dourados-MS: Embrapa Agropecuária Oeste, pp. 175.

Loos, A., Pereira, M.G., Perin, A., Beutler, S.J., Anjos, L.H.C., 2012. Carbon, nitrogen and natural abundance of $\delta 13 \mathrm{C}$ e $\delta 15 \mathrm{~N}$ of light-fraction organic matter under no-tillage and crop-livestock integration systems. Acta Scientiarum, 34, 465-472.

Macedo, M.C.M., 2009. Integração lavoura e pecuária: o estado da arte e inovações tecnológicas. Revista Brasileira de Zootecnia, 38, 133-146.
Machado, L.A.Z., Cecato, U., Jank, L., Verzignassi, J.R., Valle, C.B., 2013. Identificação e características de forrageiras perenes para consórcio com milho. in: Ceccon, G., (Ed.), Consórcio milho-braquiária. Dourados-MS: Embrapa Agropecuária Oeste, pp. 175.

Mendonça, V.Z., Mello, L.M.M., Andreotti, M., Yano, E.H., 2014. Teor e acúmulo de nutrientes no consórcio de milho com forrageiras no sistema plantio direto. Revista Brasileira de Ciências Agrárias, 9, 330-337.

Montezano, E.M., Peil, R.M.N., 2006. Sistemas de consórcio na produção de hortaliças. Revista Brasileira de Agrociência, $12,129-132$.

Oliveira, I.P., Kluthcouski, J., Yokoyama, L.P., Dutra, L.G., Portes, T.A., Silva, A.E., Pinheiro, B.S., Ferreira, E., Castro, E.M., Guimarães, C.M., Gomide, J.C., Balbino, L.C., 1996. Sistema Barreirão: recuperação/renovação de pastagens degradadas em consórcio com culturas anuais. EMBRAPACNPAF, 90 p. (Documentos, 64).

Portes, T.A., Carvalho, S.I.C., Oliveira, I.P., Kluthcouski, J., 2000. Análise do crescimento de uma cultivar de braquiária em cultivo solteiro e consorciado com cereais. Pesquisa Agropecuária Brasileira, 35, 1349-1358.

Rizvi, S.J.H., Haque, H., Singh, U.K., Rizvi, V., 1992. A discipline called allelopathy. in: Rizvi, S.J.H., Rizvi, H., (Ed.), Allelopathy: Basic and applied aspects. London: Chapman e Hall, pp. 1-10.

Rodrigues, A.P.D.A.C., Laura, V.A., Pereira, S.R., Deiss, C., 2012. Alelopatia de duas espécies de braquiária em sementes de três espécies de estilosantes. Ciência Rural, 42, 1758-1763.

Silva, D.A., Souza, L.C.F., Vitorino, A.C.T., Gonçalves, M.C., 2011. Aporte de fitomassa pelas sucessões de culturas e sua influência em atributos físicos do solo no sistema plantio direto. Bragantia, 70, 147-156.

Silva, D.V., Santos, J.B., Cury, J.P., Carvalho, F.P., Silva, E.B., Fernandes, J.S.C., Ferreira, E.A., Concenço, G., 2013. Competitive capacity of cassava with weeds: Implications on accumulation of dry matter. African Journal of Agricultural, Research, 8, 525-531. 